\title{
A Importância do Programa de Residência Docente e da Extensão da PROPGPEC do Colégio Pedro II na aplicação e desenvolvimento da nova tecnologia educacional Meditação Laica Educacional ${ }^{\circledR}$ como estratégia didático-pedagógica para uma educação emocional
}

The importance of the Teacher Housing Program and of Colégio Pedro II's PROPGPEC'S Extension on the development and application of the new educational technology Meditação Laica Educacional ${ }^{\circledR}$ as a pedagogical strategy for an emotional education

Claudiah Rato ${ }^{1}$

1 Coordenadora do Núcleo de Pesquisa em Meditação Laica Educacional Aplicada da Pró-reitoria de Pesquisa e Pós-graduação, Extensão e Cultura (PROPGPEC), Colégio Pedro II, Rio de Janeiro, Brasil. E-mail: claudiahrato@gmail.com

Recebido em: 21/08/2016 | Aprovado em: 23/04/2017

DOI: 10.12957/interag.2017.25371

\section{Resumo}

Este artigo trata do caminho traçado no desenvolvimento da pesquisa em Meditação Laica Educacional® do Colégio Pedro II, como uma inovação na Educação Básica. Apresenta como as transformações políticas ao longo de três décadas influenciaram na pesquisa-ação para o desenvolvimento de uma nova estratégia pedagógica dirigida à uma educação emocional. Descreve a metodologia utilizada para o desenvolvimento, aplicação e expansão da pesquisa. Destaca a importância de Programas como o da Residência Docente e da Extensão para o desenvolvimento das pesquisas em Meditação Laica Educacional ${ }^{\circledR}$ como estratégia pedagógica transdisciplinar dirigida à uma educação emocional possibilitando um levantamento longitudinal dos dados obtidos.

Palavras-chave: Meditação; Extensão; PesquisaAção; Meditação Laica; Educação emocional.

Área temática: Educação.

Linha de extensão: Formação de professores.

\begin{abstract}
This article deals with the path outlined by the development of the research in Meditação Laica Educacional ${ }^{\circledR}$ of Colégio Pedro II, as an innovation on Basic Education. It shows how the political changes over the last three decades influenced Participatory Action Research (PAR) on the creation of a new educational strategy that focuses on emotional education. The article describes the methodology used for the development, implementation and expansion of the research. We emphasize the importance of programs such as the Teacher Housing Program and the Extension Program for the development of the studies on Meditação Laica Educacional ${ }^{\circledR}$ as an interdisciplinary pedagogical strategy aimed at emotional education, thus enabling longitudinal evaluation of the data.
\end{abstract}

Keywords: Meditation; Extension; Participatory Action Research (PAR); Secular Meditation; Emotional Education. 


\section{Introdução}

Um dos maiores desafios da educação hoje é responder à posição de "trunfo indispensável à humanidade na sua construção dos ideais da paz, da liberdade e da justiça social" ${ }^{1}$. No ambiente escolar, o propósito do preparo para o exercício da cidadania, conforme prevê a atual Lei de Diretrizes e Bases da Educação Nacional (LDB 9.394/96), fica seriamente comprometido pela ausência de uma educação emocional. É possível constatar que, como seres humanos, ao nascermos, recebemos e aprendemos, prioritariamente, todos os cuidados físicos necessários ao nosso crescimento e desenvolvimento corporal. Após alguns anos, entramos para a escola onde recebemos e aprendemos todos os conhecimentos necessários para um bom desenvolvimento cognitivo e intelectual; porém, ao longo da vida não recebemos nenhum cuidado formal com nosso desenvolvimento emocional.

Pelo atual processo educacional podemos nos tornar doutores em determinado saber e, no entanto, ignoramos nossa dinâmica emocional a ponto de termos pouco ou nenhum controle sobre ela, fato que compromete o comportamento equilibrado tanto para atitudes desportivas quanto para o estabelecimento de relações harmoniosas no exercício pleno da cidadania.

Este trabalho apresenta uma nova proposta para a educação escolar que venha a dar conta também da educação do ser humano na sua dimensão emocional. Parte de uma pesquisa-ação que desenvolveu a nova tecnologia educacional nomeada Meditação Laica Educacional(MLE)® como estratégia didático pedagógica para uma educação emocional e segue na replicação da pesquisa de resultados ao longo de um percurso de tempo maior onde se possa constatar de uma forma mais sólida o efeito no aumento do controle emocional e, consequentemente, a geração de jovens que consigam operacionalizar suas vocações com os conhecimentos adquiridos não só para ingressarem no mercado de trabalho, mas para serem mais tolerantes e respeitosos das diferenças pessoais e culturais. 
$\mathrm{Na}$ prática do cotidiano escolar, a eficácia da educação é constantemente checada através da atitude dos alunos, principalmente em momentos fora do controle da sala de aula, no exercício da sua cidadania. Esse é o momento em que o aluno expressa o que ele efetivamente internalizou, quer aprovemos ou não.

Coube ao relatório para a UNESCO da Comissão Internacional de Educação para o século XXI, a tarefa de fornecer a leitura filosófica desse desafio para que possamos intervir.

É certo que há muitos outros problemas a resolver, chegaremos lá. Mas este relatório surge numa altura em que a humanidade, perante tantas desgraças causadas pela guerra, pela criminalidade e pelo subdesenvolvimento, hesita entre a fuga para a frente e a resignação. Vamos propor-lhe uma outra saída. Tudo nos leva, pois, a dar novo valor à dimensão ética e cultural da educação e, deste modo, a dar efetivamente a cada um, os meios de compreender o outro, na sua especificidade, e de compreender o mundo na sua marcha caótica para uma certa unidade. Mas antes, é preciso começar por se conhecer a si próprio, numa espécie de viagem interior guiada pelo conhecimento, pela meditação e pelo exercício da autocrítica. ${ }^{2}$

O que se desenhou no passado parece insuficiente para abarcar a riqueza do presente. Ao mesmo tempo, nessa era de grande avanço tecnológico, a abundância de novidades causa a sensação de perda dos referenciais teóricos norteadores para prática e crítica de uma Educação eficaz.

Para um movimento legítimo que venha a dar conta desse desafio é desejável que surjam novas alternativas. No entanto, será fundamental que elas não venham a se perpetuar como alternativas gerando apenas movimento e não mudança efetiva. Por outro lado, uma resposta somente teórica a essa necessidade de mudança que venha a se refletir numa bagagem curricular cada vez mais pesada já não é possível nem mesmo adequada.

Como professora do Colégio Pedro II (CPII), do Departamento de Educação Física (DEF), ao longo de 32 anos de magistério dedicados exclusivamente à Educação 
Básica (EB), pude presenciar o surgimento de inúmeras estratégias didático-pedagógicas desenvolvidas por colegas de várias disciplinas para vencer os desafios no ensino e aprendizagem dos conteúdos curriculares.

Ser parte efetiva do corpo docente do CPII ao longo de mais de três décadas, fez com que acompanhasse ao menos três gerações de alunos e duas de professores. A sala dos professores é, algumas vezes, o centro de inspiração na criação de algumas estratégias que emergem espontaneamente com a troca de informações entre os colegas sobre as dificuldades e características desafiadoras de suas turmas. A esse diálogo do cotidiano docente estão agregadas as dificuldades levantadas e discutidas em Conselhos de Classe que sempre contam com os pareceres do Setor de Supervisão e Orientação Pedagógica (SESOP) do CPII.

De uma forma menos espontânea e cuidadosamente pesquisada se deu o desenvolvimento da tecnologia da meditação laica educacional ${ }^{3}$. No entanto, posso afirmar que o tratamento mais cuidadoso e científico para esse desenvolvimento foi inspirado pelo lamento em assistir iniciativas criativas e eficazes de meus colegas desaparecerem com o evento de sua aposentadoria.

O cuidado no desenvolvimento desta estratégia inovadora dirigida à educação emocional contou com a metodologia da pesquisa-ação realizada durante três anos (20062009) até a sua definição como variável independente. A partir da estruturação da nova estratégia pedagógica, sua aplicação e os primeiros resultados foram publicados no livro Meditação Laica Educacional para uma educação emocional ${ }^{3}$ que resume a dissertação de mestrado que a aprovou.

Através do Programa de Residência Docente do CPII, iniciado em 2012 e financiado pela Coordenação de Aperfeiçoamento do Ensino Superior (CAPES), mais de 200 professores foram treinados nessa estratégia e dois Seminários foram realizados com a apresentação de pesquisas e relatórios de experiência de professores de diferentes níveis e disciplinas da educação básica seguindo a metodologia da pesquisa-participante. Os 
resultados apresentados por estes professores corroboram os resultados da pesquisa original e podem ser encontrados na Revista Meditação Laica Educacional do Portal Espiral do CPII.

Em Maio de 2015, foi criado o Núcleo de Pesquisas em Meditação Laica Educacional Aplicada para orientar, expandir e reunir dados da pesquisa de resultados.

Atualmente, a Extensão da Pró-reitoria de Pós-graduação, Pesquisa, Extensão e Cultura (PROPGPEC) do CPII vem colaborando com a pesquisa de resultados ampliando a possibilidade de formação de mais professores de qualquer nível e disciplina. Este relato pretende esclarecer o caminho do desenvolvimento da pesquisa, seu contexto político pedagógico e a importância dos programas de extensão dos Institutos Federais de Educação para a realização de pesquisas no nível da Educação Básica protagonizadas por seus atores principais: professores e alunos. Os resultados obtidos até agora apontam que a MLE® colabora para o aumento da atenção dos alunos em sala otimizando o tempo de aula, para a maior concentração dos alunos nos estudos melhorando seu desempenho escolar e, principalmente, um aumento de tolerância nas relações interpessoais.

\section{Contexto Político-Pedagógico}

A Meditação Laica Educacional@ emerge dentro do contexto educacional do início deste milênio quando o corpo docente do CPII, dando seguimento à incumbência passada pelo Ministério da Educação e Cultura do Brasil de apresentar seu Projeto Político Pedagógico de acordo com a nova Lei de Diretrizes e Bases (LDB) 9.394/96, realizava uma análise do processo de construção do ensino por competências.

O Ensino por Competências (EC) está inspirado no trabalho de Perrenoud ${ }^{4}$ que visa considerar a formação integral dos estudantes em todas as suas dimensões. $\mathrm{O}$ novo Projeto Político Pedagógico (PPP) veio a substituir o antigo Plano Geral de Ensino (PGE) e como professora do Departamento de Educação Física e Folclore (DEFF) fiz parte 
desse projeto em que, em 2001, foram elencadas pela primeira vez as competências específicas para a Educação Física do Colégio Pedro II.

Essa mudança de perspectiva gerada pelo novo PPP levou o DEFF a considerar a Educação Física do ponto de vista "interdisciplinar, considerando-a indissociável das demais disciplinas e assumindo um campo de atuação mais amplo do que o tradicionalmente representado, restrito aos conteúdos desportivos" ${ }^{5}$. A princípio, a prática acompanhava a nova perspectiva pedagógica fazendo com que os exercícios de aprendizagem do esporte passassem a ser um meio através do qual o aluno pudesse se perceber e se desenvolver nas áreas previstas pelo planejamento, mas, ainda assim, continuava distante da concretização da nova proposta pedagógica que orientava a educação centrada no desenvolvimento de competências no sujeito/aluno.

À medida que a implantação da nova proposta pedagógica avançava mudava, também, a formulação dos objetivos de ensino trazendo consigo a necessidade de mudança dos conteúdos da aprendizagem. O sistema de avaliação dos alunos passou a ser orientado por "enfoque de conteúdo" permitindo ao professor transcender a definição limitada de conteúdo apenas como matéria a ser transmitida. Em Ventura et al. ${ }^{6}$, essa nova perspectiva aparece como uma convocação, como vemos a seguir:

$\mathrm{Na}$ perspectiva do ensino por competências, os atuais enfoques de conteúdos vão além das "representações" sugeridas pelas conceituações propostas. Assim, assumimos não nos determos em uma prática ortodoxa, conteudista que define, por exemplo, o desporto como um conteúdo que deve ser avaliado posteriormente pela desenvoltura e/ou performance. O DEFF busca focar cada conteúdo apresentado no PPP de uma maneira bem mais ampla, reflexiva e abrangente, convocando coordenadores pedagógicos, professores e alunos a darem, coletivamente, novos rumos para a ação pedagógica.

Todo esse processo abriu espaço dentro do DEFF do CPII para que se ampliassem as discussões sobre os métodos e formas organizativas do ensino de modo que fossem contextualizados e adequados às novas demandas históricas, culturais, sociais, políticas e econômicas do mundo atual. 
Na disciplina de Educação Física, a autoestima, a cooperação, a criticidade, respeito coletivo, autonomia e solidariedade obtiveram destaque como conteúdos a serem desenvolvidos e avaliados. No entanto, ainda diante de uma circunstância de estresse e pressão emocional, não havia êxito em desenvolver o autocontrole como competência necessária para evitar um comportamento que pode colocar todos esses valores em derrocada fazendo emergir uma atitude violenta e antissocial. E, vale destacar, isso se dá independente da habilidade do aluno no esporte ou do seu desempenho escolar. A questão que se impôs, então, tratava de como ajudar o aluno a desenvolver controle emocional para valer-se das competências adquiridas de modo a se relacionar de forma harmoniosa no exercício pleno de sua cidadania?

A educação física havia de contribuir de modo eficaz para a construção da atitude cidadã do aluno principalmente por tratar de conteúdos ligados diretamente as relações sociais harmoniosas tão necessárias ao convívio social e tão desafiadas durante as situações de jogo.

No atual processo educacional percebemos a grande lacuna que há com relação ao desenvolvimento de estratégias formais dirigidas à educação emocional. Isto compromete o comportamento equilibrado tanto para atitudes desportivas quanto para o estabelecimento de relações harmoniosas no exercício pleno da cidadania segundo estabelece nossa LDB atual.

Facilitar as relações sociais harmoniosas é, também, um dos quatro pilares sugeridos pela UNESCO como princípios da educação. Segundo o Relatório para a UNESCO da Comissão Internacional sobre Educação para o século XXI, são quatro os pilares da Educação: Aprender a conhecer, Aprender a fazer, Aprender a viver juntos (ou aprender a viver com os outros) e Aprender a ser. 


\section{Origem da Meditação Laica Educacional@: A Pesquisa}

$\mathrm{Na}$ área educacional, até bem pouco tempo o tipo de pesquisa mais comum era a etnográfica. A etnografia, no início dos anos 70 surgiu como tentativa de aproximação do pesquisador da realidade educacional motivada pelo estudo das questões de sala de aula. Em ANDRÉ ${ }^{7}$, lemos:

Quando os estudiosos das questões educacionais recorreram à abordagem etnográfica, eles buscavam uma forma de retratar o que se passa no dia-a-dia das escolas, isto é, buscavam revelar a complexa rede de interações que constitui a experiência escolar diária, mostrar como se estrutura o processo de produção de conhecimento em sala de aula e a inter-relação entre as dimensões cultural, institucional e instrucional da prática pedagógica. O objetivo primordial desses trabalhos era a compreensão da realidade escolar para, numa etapa posterior, agir sobre ela, modificando-a".

No caminho da evolução da pesquisa etnográfica foi encampada a abordagem antropológica que exigiu do pesquisador o uso do procedimento de observação participante. Atualmente, a pesquisa etnográfica se encontra lado a lado com a pesquisaação e/ou pesquisa participante.

A metodologia desta pesquisa é defendida por pesquisadores que afirmam que se pode "partir da realidade social na sua complexidade, na sua totalidade quantitativa e qualitativa, na sua marcha histórica humana, também dotada de horizontes subjetivos e depois construir métodos adequados para captá-la e transformá-la”. ${ }^{8}$

Segundo $\mathrm{Gil}^{9}$, este tipo de pesquisa é realizada especialmente quando o tema escolhido é pouco explorado e torna-se difícil formular hipóteses precisas e operacionalizáveis sobre ele. Parte de uma visão geral, do tipo aproximativo e, geralmente serve para a geração de problemas mais precisos e hipóteses pesquisáveis no futuro. De todos os tipos de pesquisa é a que apresenta menor rigidez no planejamento.

Em 2006, como professora de Educação Física do Campus Humaitá II, durante a regência de minhas turmas de Ensino Médio, iniciei a pesquisa-ação que ao longo de três anos desenvolveu a técnica da meditação laica educacional® com o objetivo 
de apresentar uma proposta pedagógica que venha dar conta da formação integral do cidadão conforme as mais recentes exigências dos organismos nacionais e internacionais incluindo sua dimensão emocional.

Definido o objetivo, realizei de forma prioritária, a pesquisa sobre a definição do conceito de emoção e regulação emocional tendo o cuidado de diferenciar emoção de afeto e sentimento ${ }^{10}$. Realizei também, um cuidadoso levantamento dos procedimentos comuns às diferentes práticas de meditação e seus resultados ainda pouco pesquisados na área educacional em sua aplicação para regulação emocional ${ }^{11}$. Pude contabilizar que a maioria das pesquisas sobre a prática da meditação ainda se concentra na área da saúde.

O ambiente de mudança político-pedagógica e a demanda por conta da construção do novo PPP que ocorria no Colégio Pedro II, fez com que a metodologia da pesquisa-ação defendida pelos autores acima fosse adotada para vencer o desafio "da distância extrema entre o desenvolvimento de conhecimentos e a capacidade prática de enfrentamento dos problemas" ${ }^{12}$ que costuma ser característica dos métodos clássicos de pesquisa.

Durante todo o tempo, tanto para a leitura e organização do campo e metodologia desta pesquisa quanto para a construção da dissertação que aprovou o tratamento da variável independente, sustentei a perspectiva do método do pensamento complexo $^{13}$. Aqui o método é apresentado como caminho, ensaio gerativo, considerando que a realidade se compõe de situações complexas onde não há apenas determinismos, mas também acasos. Por isso alerta para a necessidade de se devolver, na educação, o papel ativo do sujeito cognoscente de onde foi "excluído por um objetivismo epistemológico cego". ${ }^{14}$

Este método transcende, sem deixar de considerar, a dualidade presente em todo o processo educacional que trabalha o indivíduo para integrá-lo à sociedade. Admite o fato de que essa dualidade se complexifica tanto no sujeito da variável dependente, o 
aluno, como no professor-pesquisador, gerador (pesquisa-ação) e, aplicador (pesquisaparticipante) da variável independente.

A possibilidade de uma prática pedagógica para uma educação emocional surgiu a partir do suporte teórico adquirido na minha formação como psicóloga e pode ser fator de extrema importância para permitir à escola contribuir para que esse aluno possa vir a se constituir um cidadão a partir de si mesmo, respeitando seus limites e o de terceiros, usufruindo e desenvolvendo suas habilidades de modo que o atendimento das demandas sociais não o desequilibre assim como, sua exposição ao diferente não o ameace.

No campo desta pesquisa e, seguindo o objetivo que deu origem a MLE® o aluno foi, ao mesmo tempo, o campo e a meta da pesquisa. A metodologia da pesquisaação apresentou-se como articulação fundamental não somente para garantir a presença do sujeito para quem se constrói o conhecimento, mas principalmente para gerar conhecimento diretamente aplicável dentro das condições da realidade presente. Atribuímos a isso o fato de encontrarmos resultados que demonstraram que o aluno aprovou a nova prática com entusiasmo compartilhado socialmente, que obteve os resultados imaginados e esperados e que apoia a inclusão oficial da nova estratégia no currículo escolar (diferente das atividades extraclasse) mesmo que não tenha sido esse o mesmo aluno que participou do processo que construiu essa tecnologia ${ }^{15}$.

Não se tratou de levantar dados para uma nova metodologia, mas de valorizar novos procedimentos pedagógicos. Portanto, um dos pontos importantes na adoção da metodologia da pesquisa-ação e do método do pensamento complexo é a possibilidade de se chegar a resultados positivos ou a procedimentos inovadores, a partir do atendimento de uma demanda do próprio aluno onde o professor foi solidário no processo.

As práticas pedagógicas são em sua ampla maioria orientadas por métodos dirigidos a criar estratégias para passagem de conhecimento, pois importava-nos saber como dividir e organizar o conhecimento para que ele fosse devidamente apreendido pelo 
aluno. Sem implicar no extermínio desse caminho, pude traçar um outro paralelo que possibilita a criação de uma proposta que inclua estratégias pedagógicas para se desenvolver o sujeito do aprendizado e não o aprendizado no sujeito. Particularmente ajudá-lo a se educar emocionalmente.

A meditação liberta o sujeito do compromisso com a meta de modo a valorizar a experiência do momento presente a partir de si mesmo. Essa experiência que liberta o pensamento ao erro e à incerteza humana vem sendo, segundo Morin ${ }^{16}$, "tantas vezes deixada de lado pela atividade acadêmica e intelectual e, hoje tão necessária para educar e educar-nos". A maior tolerância nos relacionamentos ${ }^{17}$ e o maior equilíbrio emocional ${ }^{18}$ diante do desafio mais importante para o aluno do Ensino Médio - a prova - parece apontar para uma preciosa prática pedagógica que venha ao encontro do propósito final da Educação apontado no início deste relatório. Cabe à escola educar, também, emocionalmente com o compromisso de formar um cidadão equilibrado na construção de uma sociedade pacífica.

\section{Função social de uma educação emocional no Ensino Médio}

O aluno do Ensino Médio enfrenta vários desafios que o levam a relegar as aulas de Educação Física a um segundo plano. Do ponto de vista da sociedade, seu desempenho escolar é, praticamente, a única referência para uma avaliação do seu caráter em construção. Isso faz com o foco pessoal nesse período seja quase totalmente dirigido à sua capacidade de adquirir conhecimento para garantir um bom desempenho nos exames dos quais depende seu futuro.

Segundo Zagury ${ }^{19}$, para as camadas populares, a escola e o estudo são vistos como elementos de ascensão social, enquanto que nas camadas economicamente mais favorecidas, os pais, em sua maioria, colocam o estudo como a única obrigação dos filhos. A escola, por sua vez, espera que esse aluno a represente bem, engrossando o número de 
aprovados no vestibular da rede pública ou privada. Seguindo essa tendência, observamos que a maioria dos estudos de grandes autores dirigidos aos sujeitos dessa faixa etária se preocupam com o que podem aprender, assimilar ou desenvolver-se em termos intelectuais e sociais. No entanto, é interessante notar que quando o jovem é perguntado sobre o que o fará feliz, Zagury ${ }^{20}$ publica:

"Felicidade para nós é, primeiramente ficar com a pessoa que amamos, em segundo lugar construir ou pertencer a uma família que se entenda bem e viva harmoniosamente, e, em terceiro, ter um trabalho que remunere bem. Só assim poderemos nos dizer realizados.”

Ou seja, surpreendentemente, para um futuro cidadão julgar-se realizado, na palavra dele mesmo, prioritariamente, ele deve ter habilidades que garantam bons relacionamentos e, apenas em terceiro lugar, um trabalho que o remunere bem.

Apesar da forte tendência de, atualmente, o ensino médio estar focalizado no desempenho intelectual, verificamos que o conceito do desenvolvimento de competências trazido por Perrenaud ${ }^{21}$ desperta a escola para o conteúdo subjetivo do aluno levando-a a considerar que deve formar um aluno capaz de gerenciar conhecimentos e não apenas desenvolver capacidades ou instrumentos para que ele possa adquiri-los.

Embora alguns autores como Perez ${ }^{22}$; Trent, Russell e Cooney ${ }^{23}$ e Sacristan ${ }^{24}$ incluam a autoimagem e o autoconceito como alguns dos fatores importantes de serem levados em conta, também, para o bom rendimento escolar, o conflito interno emocional vivido por aquela personalidade que tenta emergir em sua singularidade em meio a tantas demandas não encontra assistência educacional formal a não ser quando já se tornou um problema. O autoconceito, formado através das relações interpessoais que se dão, também, dentro da escola, é fator fundamental na construção da autoestima que, por sua vez, influenciará não só o desempenho escolar do aluno, mas também seu estilo de vida e a construção de valores como cidadão. 
É na busca de uma identidade única e pessoal $^{25}$ que esse aluno desafia regras e autoridade como um caminho para estabelecer-se como indivíduo ao mesmo tempo que não quer perder a ligação com o grupo que o identifica. É raro um adolescente aceitar imposições e isso faz parte do seu desenvolvimento, esses conflitos possibilitam o seu amadurecimento. O Setor de Supervisão e Orientação Pedagógica (SESOP), na maioria das vezes, age como harmonizador desse tipo de conflito interno quando ele já escapou ao controle do próprio adolescente, atingindo a esfera social.

A importância do Programa de Residência Docente do CPII e de Programa de Extensão para a ampliação e seguimento da pesquisa em MLE®

O cuidado na preservação dos atores e usuários dessa estratégia, a saber professor e aluno, revela desafios na continuidade da pesquisa científica que não devem ser superados através da supressão da própria pesquisa ou da mudança de seus atores sob pena de manter a relação professor x aluno e as estratégias de aprendizagem tão defasadas do desenvolvimento das tecnologias que nos cercam.

Nessa perspectiva, mais uma vez, uma mudança no contexto político pedagógico do Colégio Pedro II favorece essa ação. Com a transformação em Instituto Federal de Educação houve a criação da Pró-reitoria de Pesquisa, Pós-graduação, Extensão e Cultura. A partir de 2012, houve a criação do Programa de Residência Docente no Colégio Pedro II, patrocinado pela Coordenação Acadêmica de Pesquisa no Ensino Superior (CAPES).

Faz parte do Programa de Residência Docente do Colégio Pedro II o cumprimento de uma carga horária em oficinas e seminários apresentados dentro do programa. Essas oficinas, seminários e, atualmente (2015-16) minicursos são oferecidos ao longo ano em três ciclos. Desde então, em vários ciclos foram realizadas dezessete oficinas em Meditação Laica Educacional® e mais de 200 professores formados. 
Desenvolvida, definida e apresentada como estratégia didático-pedagógica para uma educação emocional, esta oficina formou professores de qualquer nível de ensino e de qualquer disciplina. Os dados abaixo foram levantados da amostra dos 31 professores inscritos na terceira turma da oficina de Meditação Laica Educacional dentro do Programa de Residência Docente edição 2013, ciclo 1. Em 2012, já haviam ocorrido duas oficinas uma no Ciclo II e outra no Ciclo III.

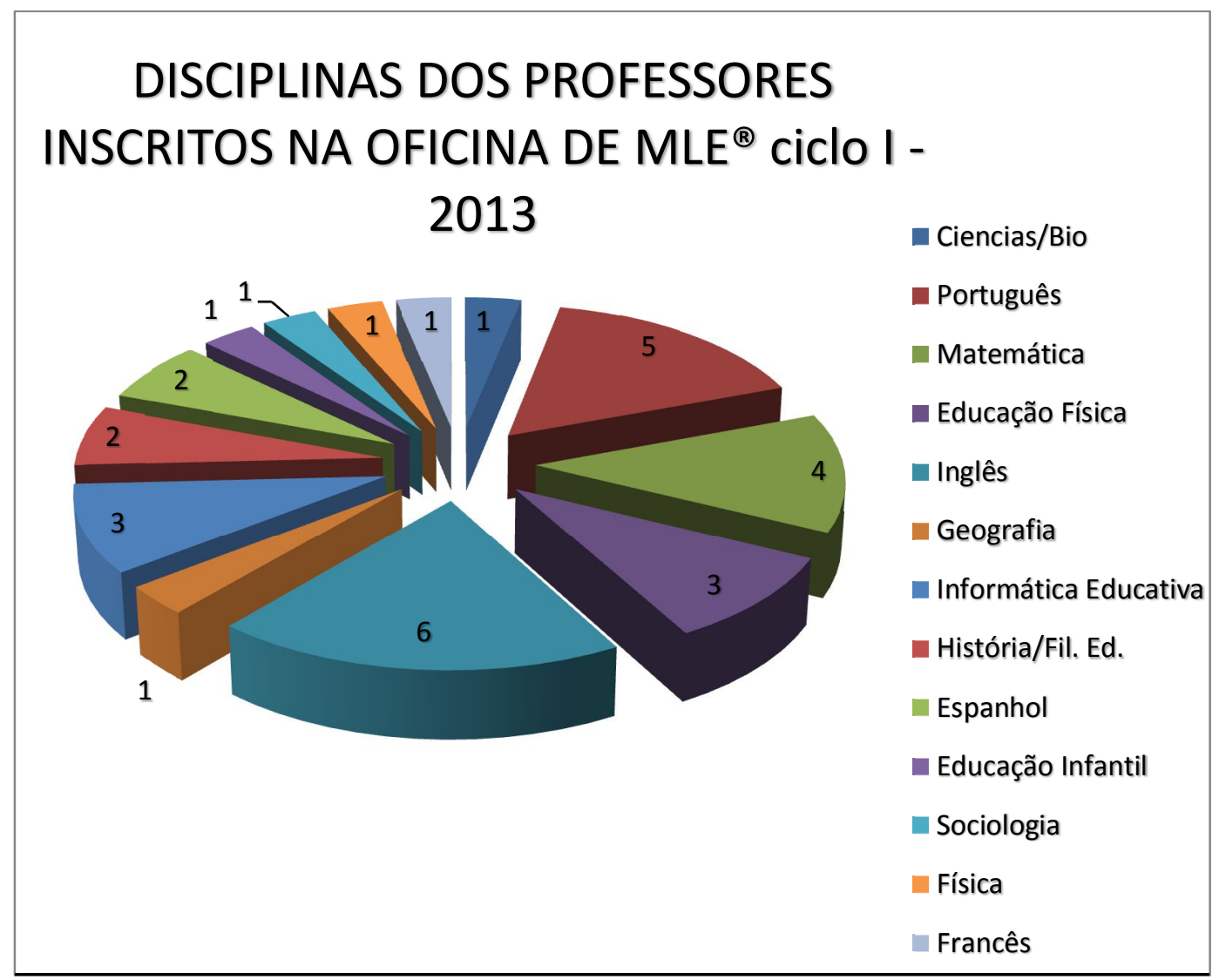

Gráfico 1: Disciplinas dos professores inscritos na turma de Meditação Laica Educacional ciclo 1 de 2013.

Ao serem perguntados se havia intenção em aplicar o conteúdo aprendido na oficina obtivemos o seguinte resultado. 


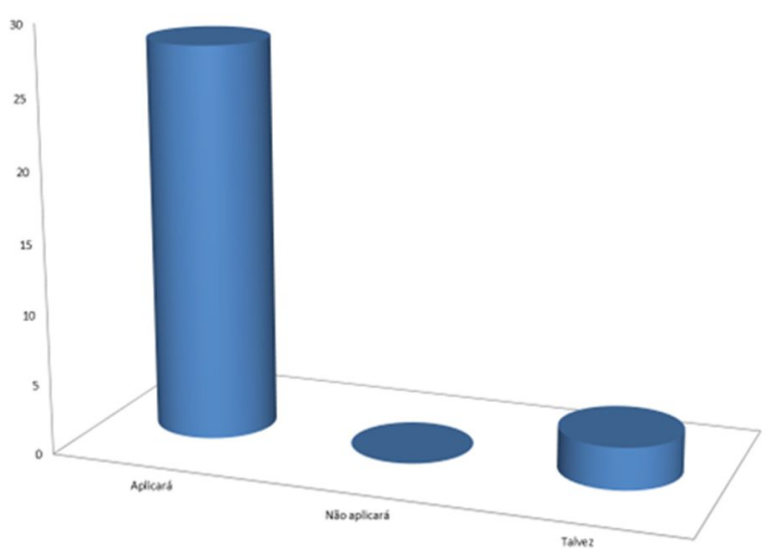

Potencial de Aplicabilidade

Gráfico 2: Potencial de aplicabilidade

O alto potencial de aplicabilidade se confirmou quando, ao final de 2013 , os professores que aplicaram a MLE® levados pelo entusiasmo dos resultados obtidos pediram que fosse realizado um Seminário para que pudessem apresentar seus trabalhos. Nesse Seminário, outubro de 2013, sete professores se apresentaram com os dados de suas pesquisas e alguns relatos de experiência.

\begin{tabular}{|c|c|}
$\begin{array}{c}\text { Professores que } \\
\text { apresentaram seus } \\
\text { trabalhos }\end{array}$ & $\begin{array}{c}\text { Disciplina e nível de } \\
\text { ensino }\end{array}$ \\
\hline Prof Grasiella Martins & $\begin{array}{c}\text { Educação Física - Ensino } \\
\text { Fundamental }\end{array}$ \\
\hline Profa Ana Antunes & $\begin{array}{c}\text { Anos Iniciais } \\
\text { Educação Física - Ensino } \\
\text { Fundamental }\end{array}$ \\
\hline Prof Gabriela Conde & $\begin{array}{c}\text { Biologia - Ensino Médio } \\
\text { Português - Ensino } \\
\text { Fundamental }\end{array}$ \\
\hline Prof Sérgio Silva & $\begin{array}{c}\text { História - Classe de } \\
\text { autonomia }\end{array}$ \\
\hline Prof Jair Silva & Inglês - Ensino Médio \\
\hline Prof Andrea Pereira & Tallin
\end{tabular}

Tabela 1 
Em 2015, no II Seminário em Meditação Laica Educacional Aplicada, mais sete professores apresentaram suas pesquisas. As pesquisas destes professores estão publicadas na revista meditação laica educacional do Portal Espiral do CPII (https://www.cp2.g12.br/ojs/index.php/meduc), em forma de dois artigos, duas comunicações orais e três relatos de experiência.

Os resultados obtidos corroboram os resultados da pesquisa original reforçando a possibilidade de estarmos diante, se não de uma estratégia eficaz para o desenvolvimento de uma educação emocional, o primeiro passo para o seguimento de pesquisas científicas nesse âmbito.

O critério de seleção de professores meditadores laicos pesquisadores ocorre da mesma maneira que a adesão dos alunos à prática, ou seja, voluntária. Para isso, a oportunidade de formação de professores atuantes na educação básica nesta estratégia vem sendo ampliada de forma a aumentarmos o levantamento de dados de professores meditadores laicos e seus resultados de aplicação desta estratégia à pesquisa, preservandose a metodologia da pesquisa-participante.

Em 2016, atingida pelo corte de gastos no orçamento, a CAPES deixou de dar continuidade e sustentação ao programa desde 2016. O Colégio Pedro II passa então, a subsidiar o Programa de Residência Docente através da Pró-reitoira de Pós-graduação, Pesquisa, Extensão e Cultura (PROPGEPC) garantindo assim sua continuidade. Até então, esta era a única oportunidade para a formação de professores em MLE® pelo meio público e acadêmico. Nesse mesmo ano, a PROPGPEC no seu braço da Extensão lança o curso de Formação em Meditação Laica Educacional® ${ }^{\circledR}$ com o público-alvo dirigido exclusivamente a professores de qualquer disciplina ou nível de ensino, com aulas teóricas à distância deixando a parte presencial focalizada no treino da técnica, proporcionando uma grande ampliação na oferta dessa formação para professores. Das 20 vagas oferecidas, 
tivemos todas preenchidas imediatamente, formando uma lista de espera de 47 professores.

Portanto, creio fundamental destacar que a importância do braço da Extensão no ensino universitário pode se aplicar aos Institutos Federais da Educação (IFEs), contribuindo nesse âmbito para o desenvolvimento de estratégias pedagógicas mais afinadas com a realidade prática do ensino básico guardadas as suas peculiaridades. Nez $\&$ Nesser $^{26}$, em recente publicação escrevem:

Considera-se, então, que há necessidade de ampla divulgação dos projetos para a comunidade acadêmica. Para que possam despertar a curiosidade, o interesse e a participação dos acadêmicos, não apenas como bolsistas, mas, como colaboradores e/ou voluntários ativos no processo. É imprescindível destacar, por fim, que a universidade que desempenha o tripé constitucional (ensino, pesquisa e extensão) consegue assimilar as demandas sociais e incorporá-las em suas ações cotidianas, o que fortalece as IES que têm como foco o atendimento da sociedade em geral.

Segundo o Portal público na internet do Colégio Pedro II (www.cp2.g12.br) , a missão da Extensão é a de "promover a articulação entre o ensino e a pesquisa desenvolvidos no CPII e as demandas da sociedade, através de programas, projetos, eventos, cursos e demais atividades de extensão, considerando o compromisso do Colégio enquanto instituição pública empenhada na ação reflexiva de questões sociais e na difusão do conhecimento para a superação das desigualdades sociais." Esta articulação entre ensino e pesquisa é fundamental no nível da Educação Básica para que seus resultados estejam em níveis aplicáveis e responsáveis aos desafios peculiares a esse nível da Educação Nacional.

\section{Conclusão}

A criação de novas estratégias pedagógicas tem na sala de aula seus atores em um campo legítimo para pesquisas e encontra na metodologia da pesquisa- ação e 
pesquisa-participante os procedimentos adequados para o desenvolvimento de soluções diretamente aplicáveis no complexo universo escolar.

A complementaridade entre as dimensões do ensino e pesquisa relacionadas a novas estratégias pedagógicas no nível da educação básica é aconselhável para que essas estratégias saiam do campo da espontaneidade extra-acadêmica. As estratégias didáticopedagógicas costumam se desenvolver a partir da criatividade e talento do professor e, geralmente, desaparece com ele com o evento de sua aposentaria ou qualquer outro motivo que o afaste da sala de aula.

Os professores da educação básica têm nos Institutos Federais de Educação, por sua vez, a possibilidade da aplicação de um conceito dinâmico no âmbito do processo de aprendizagem e construção de conhecimento que vem ao encontro da necessidade de uma visão mais profunda e complexa da realidade. Complexa, segundo o método que norteou essa pesquisa. $\mathrm{O}$ pensamento complexo, ao contrário de problematizar uma questão, procura complexificá-la acolhendo todas as variáveis que atuam na realidade sobre a qual se pretende agir.

Diante das mudanças de hábitos causadas pelas inovações tecnológicas tornouse necessária a criação de práticas pedagógicas que considerassem esses novos hábitos de modo a auxiliar o professor no exercício de uma boa regência de turma, ajudando o aluno a manter-se presente e atento, viabilizando a compreensão e o acompanhamento do currículo escolar.

A presença do aluno no processo de pesquisa-ação permitiu que o propósito na criação e desenvolvimento desta estratégia pedagógica atendesse o aluno em sua demanda. O professor foi solidário, organizador, pesquisador e avaliador dos resultados. As categorias surgidas como benefícios citados com a prática da Meditação Laica Educacional ${ }^{\circledR}$ partiram do discurso direto do aluno. É pertinente apontar que a presença do aluno e professor no processo de pesquisa-ação seja um fator de grande responsabilidade nos resultados positivos e satisfatórios para ambos. 
Em virtude do volume de dados destes resultados que se acumularm foi criada a revista Meditação Laica Educacional que, até o momento, se propõe a funcionar como banco de resultados da MLE® aplicada. O Programa de Residência Docente assim como a Extensão dos Institutos Federais de Ensino Colégio Pedro II, foram fundamentais na instauração da pesquisa com coleta de dados longitudinais e guardam a mesma importância encontrada no ensino universitário na sustentação do tripé ensino-pesquisa e extensão, mas aqui, considerando as peculiaridades da Educação Básica que não se assemelham ao ensino superior. Qualquer inovação nesse nível de ensino que parta de seus atores, professores e alunos tem grande vantagem uma vez que incluem a realidade cotidiana em sua diversidade e limitações.

Os resultados obtidos até o presente momento apontam a meditação laica educacional ${ }^{\circledR}$ como uma técnica capaz de transpor as diversidades culturais, sociais, econômicas e pessoais que compõem as diferentes salas de aula nas quais foi aplicada, uma vez que vem levantando os mesmos resultados da pesquisa original: maior atenção, maior concentração em sala de aula e maior tolerância nas relações interpessoais. De forma mais aleatória, encontramos resultados que demonstram o aumento da autoestima nos estudantes praticantes.

Apesar dos resultados alcançados até agora reconhecemos ser preciso ampliar o campo de pesquisa. Os programas dirigidos à formação continuada de professores e os projetos de extensão dos Institutos Federais de Educação têm sido fundamentais para a construção desse conhecimento e para a superação das desigualdades sociais. Através do caminho do pensamento complexo, ao contrário de termos tais desigualdades afirmadas ou reconhecidas para que então combatidas, a estratégia da meditação laica educacional ${ }^{\circledR}$ trilha a via da oferta de uma oportunidade ao aluno de visitar-se, de conhecer-se e reconhecer a partir de si mesmo sua singularidade e aceitá-la. Psicologicamente, a autoaceitação é um dos fatores que deixa o sujeito menos vulnerável ao ambiente externo e esta prática pode possibilitar ao aluno deparar-se com o diferente sem que isso o ameace 
e, portanto, sem ter o impulso de se defender de forma reativa. O comportamento descrito na categoria "maior tolerância nas relações interpessoais" aponta o que se pretende alcançar com uma estratégia pedagógica dirigida a uma educação emocional.

\section{Referências}

1. DELORS et al. Educação: Um Tesouro a Descobrir. Relatório para a UNESCO da Comissão Internacional sobre Educação para o século XXI. Cortez Editora, São Paulo, 1998.

2. DELORS et al. Educação: Um Tesouro a Descobrir. Relatório para a UNESCO da Comissão Internacional sobre Educação para o século XXI. São Paulo, Cortez Editora, 1998.p.53

3. RATO, C. Meditação Laica Educacional para uma educação emocional. São Paulo: Paco editora, 2011.

4. PERRENOUD, P. Construir as competências desde a escola. Porto Alegre: Artes Médicas, 1999.

5. VENTURA C., DA SILVA K., SANTORO M., DE SÁ M. Ensino por Competências: uma Abordagem Renovadora no Cotidiano da Educação Física do Colégio Pedro II. Revista Contemporânea de Educação da Faculdade de Educação da Universidade Federal do Rio de Janeiro (UFRJ) - no 06 Rio de Janeiro, v. 3, n. 6. julho/dezembro 2008

6. VENTURA C., DA SILVA K., SANTORO M., DE SÁ M. Ensino por Competências: uma Abordagem Renovadora no Cotidiano da Educação Física do Colégio Pedro II. Revista Contemporânea de Educação da Faculdade de Educação da 
Universidade Federal do Rio de Janeiro (UFRJ) - no 06 Rio de Janeiro, v. 3, n. 6. julho/dezembro 2008 P.320

7. ANDRÉ, M. E. D. A de. Tendências atuais da pesquisa na escola, in Cadernos CEDES v. 18 n. 43 Campinas. http://www.scielo.br doi: 10.1590/S010132621997000200005. Versão impressa ISSN 0101-3262, Dezembro de 1977. Acesso 21 de agosto de 2016.

8. Demo, Pedro. Metodologia científica em ciências sociais. 1989.p.229.

9. GIL, A. C. Métodos e Técnicas de Pesquisa Social. São Paulo: Ed. Atlas S.A. 2009.

10. Gross,J.J. \& Thompson, R.A. Emotional Regulation: Conceptual Foundations. In J.J. Gross (Ed.) Handbook of Emotion Regulation. New York. Guildford Press. 2006. http://med.stanford.edu/nbc/articles/4\%20-\%20Emotion\%20Regulation\%20\%20Conceptual\%20Foundations.pdf. . Acesso em 23/09/2010.

11. RATO, C. Meditação Laica Educacional para uma educação emocional. São Paulo: Paco Editorial, 2011.

12. Demo, Pedro. Metodologia científica em ciências sociais. 1989, p. 233

13. Morin, E., Ciurana E-R., Motta R. D. Educar na Era Planetária: o pensamento complexo como método de aprendizagem no erro e na incerteza humana. Brasília: Ed. Cortez, UNESCO, 2009.

14. MORIN, E., CIURANA E-R., MOTTA R. D. Educar na Era Planetária: o pensamento complexo como método de aprendizagem no erro e na incerteza humana. Brasília: Ed Cortez.; UNESCO, 2009. p.37

15. Rato, C. Meditação Laica Educacional para uma educação emocional. São Paulo: Paco Editorial, 2011. pp $107-117$

16. Morin, E. Educação e Complexidade: Os Sete Saberes e outros ensaios. Maria da Conceição Almeida e Edgard de Assis Carvalho (Orgs.). 5 ed. São Paulo. Ed. Cortez. 2009 p.21 
17. RATO, C. Meditação Laica Educacional para uma educação emocional. São Paulo: Paco Editorial, 2011 p.1 24

18. RATO, C. Meditação Laica Educacional para uma educação emocional. São Paulo: Paco Editorial, 2011 p.126

19. Zagury, T. O Adolescente por Ele Mesmo. Rio de Janeiro: Ed. Record, 2002.

20. ZAGURY, T. O Adolescente por Ele Mesmo. Rio de Janeiro: Ed. Record, 2002. p. 240.

21. PERRENOUD, P. Construir as competências desde a escola. Porto Alegre: Artes Médicas, 1999.

22. Perez, V. M., Los Adolescentes ante el studio: causas y consecuencias del rendimento acadêmico. Madrid: Ed.Fundamentos.1997

23. Trent, L M Y; Russell, G; Cooney, G, Assessment of self-concept in early Adolescence, Australian Journal of Psychology; 46 (1) Apr 1994, p.21-ASSIA: Applied $\begin{array}{llll}\text { Social } & \text { Sciences } & \text { Index abstracts. }\end{array}$ http://onlinelibrary.wiley.com/doi/10.1080/00049539408259465/full. Acesso em 21 de Janeiro de 2010.

24. Sacristan, J. G., La Interaccion Social Condiciona el Rendimiento Academico, RS, Cuadernos de Realidades Sociales, vol. 6, pp. 109-136, 1975 Base de Dados Dialnet: https://dialnet.unirioja.es/servlet/articulo?codigo=3905330. Acesso em 19 de Agosto de 2016.

25. GARANTO, J. Las actitudes hacia sí mismo e su medición. Espanha: Universidad de Barcelona, 1984.

26. NEZ, E. \& ESSER, F. A extensão universitária sob foco de estudo: reflexões sobre limites e desafios in Interagir: pensando a extensão, Rio de Janeiro, n. 21, p. 01-16, jan./jun. 2016. Disponível em <http://www.epublicacoes.uerj.br/index.php/interagir/article/view/15543>. Acesso em 19 de Agosto de 2016. DOI: 10.12957/interag.2016.15543 